\title{
ONTOLOGIAS, TAXONOMIA E TESAUROS EM TEORIA DE SISTEMAS E SISTEMÁTICA
}

\section{ONTOLOGÍAS, TAXONOMÍA E TESAUROS EM TEORIA DE SISTEMAS E SISTEMÁTICA}

\section{CURRÁS, Emília. Ontologias, taxonomia e tesauros em teoria de sistemas e sistemática. Tradução Jaime Robredo. Brasília: Thesaurus, 2010. 182 p.}

A autora, com a presente obra, pretende situar as ontologias e a taxonomia no campo da Teoria da construção de tesauros, bem como a aplicação da Sistemática à Organização do Conhecimento.

O prefácio é de Emir Suaiden (IBICT), que destaca, dentre outros pontos, o pioneirismo da obra. Em seguida, há a apresentação da obra pela própria autora, que resume em três pontos as novidades que o livro introduz no estudo teórico da Ciência da Informação, bem como no mercado: primeiro, o estudo das "Ontologias e Taxonomia como sistemas de classificação de matérias, nas Ciências da Informação"; segundo, a relação da Sistemática com as Ontologias, a Taxonomia e os Tesauros, deduzindo que "a Sistemática Cladística está intimamente relacionada com as Ontologias e os Tesauros"; e, terceiro, a aplicação da Teoria Geral de Sistemas à Teoria de Tesauros.

Assim, o livro se apresenta em 5 capítulos ricos em exemplos e figuras que representam importantes recursos didáticos. Ao final de cada capítulo, a autora propõe uma série de reflexões para levar o leitor a avaliar sua compreensão sobre o que foi lido. Do mesmo modo, relaciona também "Obras de Referências" relativas ao tema de cada capítulo, permitindo ao leitor um aprofundamento naquilo que lhe é de interesse.

De início, a autora apresenta uma evolução das formas de classificação até chegar às novas teorias e uso das ontologias. Para tanto, faz uma ampla abordagem do que vem a ser o "conhecimento", passando pela questão da informação na produção deste até chegar à importância de sua organização.

Ao enfatizar que o conceito de conhecimento foi alterado por conta do uso dos computadores e da "informática aplicada aos processos informativos-documentários", a 
autora ressalta ter desaparecido o caráter subjetivo do conhecimento, que hoje é considerado sinônimo de computação.

Nesse ponto, a autora se vale de estudiosos da área para apresentar uma interessante comparação entre o funcionamento das células do cérebro humano com um sistema informático no momento da elaboração de uma nova informação, ou seja, elaboração do conhecimento.

Ao tratar da questão da "Organização do conhecimento", Currás avalia que o referido termo, ao contrário de outrora, tem aparecido com bastante frequência em publicações recentes e supõe que tal "anomalia" se deva ao crescimento de seu uso na área de informática e cibernética. Ressalta também que, no âmbito documentáriobibliotecário, o termo organização do conhecimento figura, na maioria dos casos, como sinônimo de sistema de classificação (temática).

Embora os sistemas de classificação tenham se tornado mais flexíveis de modo a permitir a inclusão de novos termos que surgem de acordo com a evolução da sociedade, com o advento da informática, as classificações como hoje se apresentam já não mais atendem a nova realidade.

Nesse novo mundo da informática, já se fala de ontologias que, embora com estrutura muito diferente, apresentam-se como sinônimo de linguagens documentárias.

Por meio de extensa bibliografia, a autora analisa a origem das ontologias e conclui que, com a aplicação das linguagens informáticas à linguagem natural, há um rompimento da estrutura da palavra, pois, agora, se fala em bites.

Currás chama a atenção também para a escolha do termo ontologia, visto que o mesmo pertence à Filosofia e à Metafísica. Ao buscar uma definição que justifique a escolha por parte dos informáticos, opta por aquela que apresenta a ontologia como sendo "o estudo do que existe e do que admitimos que existe para conseguir uma descrição coerente da realidade" e que vê um paralelo com o processo de transformação da linguagem natural para uma linguagem codificada.

Outro conceito que mudou seu significado e também ampliou seu campo de ação foi a Taxonomia. Antes, em geral aplicada à Biologia e à Lógica, a taxonomia hoje passou a ser usada também no campo da tecnologia e no contexto das Ciências da informação no que se refere a sistemas de classificação.

Sendo a taxonomia definida como o "estudo teórico de uma classificação incluindo seus fundamentos, princípios, procedimentos e regras", a autora apresenta sua análise partindo da ordenação, passando pela classificação, pelos próprios sistemas de 
classificação até chegar às taxonomias propriamente ditas. A autora então perpassa pela sua disposição hierárquica e horizontal e traça um paralelo entre as taxonomias e os tesauros destacando suas semelhanças e suas diferenças.

Dentre as semelhanças, destaca como principal aquela que aponta para o fato de que ambos, taxonomia e tesauros, compartilham alguma utilidade comum, especificamente, a de "servir como método de classificação de linguagem; linguagem dos documentos, que contêm dados e informação potencial, suscetíveis de se transformar em informação útil."

No tocante às diferenças, destaca o fato de que os tesauros podem ser estruturados manual e tecnicamente, já as taxonomias são desenvolvidas com utilização praticamente única das tecnologias. Admite o crescimento, dia a dia, dos programas informáticos para a construção automática dos tesauros, mas ressalta que, para elaboração de tais programas, é necessário que se conheça bem "o mecanismo, a técnica, com sua teoria e prática de construção de tesauros."

Destaca também uma importante diferença quanto à utilização das taxonomias e dos tesauros. As taxonomias são utilizadas quase que exclusivamente pelos informáticos, já os tesauros constituem verdadeiros "patrimônios dos profissionais da informação e da documentação, bibliotecários incluídos."

Em seguida, a autora foca nos tesauros e busca defini-los demonstrando sua forma de construção e uso. Para tanto, faz um resgate de sua evolução histórica e apresenta os diversos tipos de tesauros existentes.

Cita como exemplo de utilidade dos tesauros, no campo da informática, o software de busca do sítio eletrônico Yahoo, que se baseia numa arquitetura da informação cujos pilares são a ontologia, taxonomia e os tesauros. Dessa forma, evidencia que tanto as ontologias quanto a taxonomia, embora apresentem diferenças, possuem, assim como os tesauros, estruturas de unidades conceituais que se "convertem em termos quando expressas em palavras específicas para cada assunto ou tema."

Ainda neste capítulo reservado aos tesauros, Currás faz uma observação que, embora não represente uma novidade, nunca é demais reforçá-la: diz acreditar que, com o desenvolvimento de programas informáticos que possibilitem o uso da linguagem natural, chegará o momento em que todas essas complicações de relações entre os termos das linguagens documentárias tornar-se-ão desnecessárias. No entanto, alerta que tal fato só servirá para aliviar o trabalho do usuário e talvez daquele profissional que atua nas buscas de informação, mas não livrará os analistas que tornam possível a 
recuperação da informação de conhecer muito bem como estabelecer as relações entre os termos e como coordenar os conceitos. É enfática ao afirmar que "não são as máquinas que fazem o esforço intelectual. São os seres humanos que o fazem".

Talvez a maior novidade da presente obra inicie-se a partir do Capítulo IV, no qual a autora aplica a Sistemática Claudística à Teoria da Construção de Tesauros com o intuito de reforçar a própria Teoria da Construção de Tesauros. Demonstra a evolução da Sistemática, apresentada aqui na sua acepção mais comum, ou seja, um "método ou forma de se obter classificações..., para qualquer coisa", e enfatiza a sua aplicação na área de Biologia.

Ao relacionar a Sistemática com a Teoria da evolução, de Darwin, a autora a define como a "ciência da diversidade, ou seja, a ciência da organização do conjunto total do conhecimento sobre os organismos" e destaca que uma das principais propriedades da sistemática é justamente seu componente evolutivo.

A partir da capacidade de evolução do ser vivo, premissa maior da Teoria da evolução, a autora questiona se a linguagem, suporte de todas as ideias, que evolui, transforma-se, muda, não seria ela também um ente vivo? Assim, justifica a aplicação da Sistemática à Linguística, à Terminologia e, consequentemente, às Ciências da Informação e Documentação.

Ao estabelecer as diferenças entre a taxonomia e a Sistemática, afirma que pela taxonomia se aplicam critérios de classificação formais, com uma postura estática, enquanto que a Sistemática apresenta característica mais dinâmica.

Estudiosos apresentam a Sistemática da seguinte forma: Sistemática clássica, numérica e cladística, ou Sistemática cladística, evolutiva e fenética. Para o presente estudo, a autora considerou a Sistemática cladística e a evolutiva por achar que se adequam mais à aplicação na teoria de construção e uso de tesauros.

A Sistemática Cladística, descrita por W. Henning em 1950, "supõe um nível maior de complexidade dentro da própria sistemática" e sendo a mais estudada, em 1995, chegou a se constituir uma disciplina propriamente dita, denominada Cladismo ou Cladística.

Para se conseguir classificar as inúmeras espécies de animais e vegetais, houve a necessidade de um nível maior de especificidade. Henning, então, atingiu a especificação das características dos indivíduos, o que o levou a considerar as unidades estruturais como portadoras de um mínimo de informação. A partir dessas unidades chamadas semaforontes, a autora desenvolve o raciocínio no qual o semaforonte se converte na 
unidade básica de classificação que se expressa pela unidade conceitual e, por esta ser portadora de informação, é igualmente expressa por palavra ou conjunto delas.

Dessa forma, as palavras que são portadoras de informação útil, convertem-se em palavras-chave (descritores).

Partindo dessas reflexões, a autora busca demonstrar que a Sistemática Cladística pode ser aplicada à teoria dos tesauros e que os tesauros fazem parte da Sistemática Cladística. Para reforçar essa ideia, são analisados alguns exemplos no final do capítulo. Para reforçar essa ideia, são apresentados diversos exemplos no final do capítulo.

O quinto e último capítulo Currás dedica ao estudo da Teoria de Sistemas aplicada à construção de tesauros. Começa pela análise da evolução histórica da Teoria dos Sistemas, desde a época de Platão e Aristóteles até o final do século XX, momento no qual se intensificaram os estudos dos sistemas, "chegando-se a vislumbrar que podem constituir uma nova forma de pensar: Systems Thinking, Pensamento Sistêmico, que formará uma filosofia sistêmica".

Dentre várias definições de sistemas apresentadas pela autora, a mais geral é a que define sistema como um "conjunto de entes independentes em si mesmos, que se encontram em inter-relação com eles mesmos e com o ambiente que os circunda". Nesse ponto, a autora passa a demonstrar como aplicar, na prática, a Teoria de Sistemas à Construção de Tesauros propriamente dita. Dessa forma, passa a descrever de modo simplificado os passos e os elementos a serem considerados nessa empreitada, apresentando alguns diagramas para facilitar a compreensão.

Enfim, a autora finaliza a obra reforçando a sua teoria de que "uma ontologia e uma taxonomia constituem um sistema de classificação semelhante, na sua construção, a um tesauro" e, sendo assim, poder-se-ia aplicar a Teoria dos Sistemas tanto a uma quanto a outra. Como contraponto, a autora também destaca as dificuldades dessa empreitada e a complexidade exigida nesse processo, embora afirme ser a tarefa proveitosa e útil.

Diante do exposto, retomemos a fala da autora no momento da apresentação de sua obra quando afirma ser este um "livro simples de leitura fácil". Confesso que assim não me parece. Uma obra inovadora e instigante, sem dúvida. Leitura fácil e simples, nem tanto! Fica o desafio. 